\title{
Differences in prognostic factors according to viral status in patients with hepatocellular carcinoma
}

\author{
HIROSHI AKAHOSHI, NAOTA TAURA, TATSUKI ICHIKAWA, HISAMITSU MIYAAKI, \\ MOTOHISA AKIYAMA, SATOSHI MIUMA, EISUKE OZAWA, SHIGEYUKI TAKESHITA, \\ TORU MURAOKA, TOSHIHISA MATSUZAKI, MASASHI OHTANI, HAJIME ISOMOTO, \\ TAKEHIRO MATSUMOTO, FUMINAO TAKESHIMA and KAZUHIKO NAKAO
}

Department of Gastroenterology and Hepatology, Graduate School of Biomedical Sciences, Nagasaki University, Sakamoto1-7-1, Nagasaki 852-8501, Japan

Received October 23, 2009; Accepted February 6, 2010

DOI: $10.3892 /$ or_00000766

\begin{abstract}
The number and ratio of both HBsAg- and HCV Abnegative hepatocellular carcinoma (HCC-nonBC) cases have been steadily increasing in Japan. The aim of this study was to examine the frequency of detection of HCC-nonBC by screening methods and to elucidate the clinical characteristics of HCC-nonBC compared with those of hepatitis C and/or B virus-associated HCC (HCC-virus). We recruited 624 patients with HCC who were diagnosed between 1982 and 2007 at the Department of Gastroenterology and Hepatology, Nagasaki University Hospital. They were categorized into 2 groups as follows: i) 550 were included in the HCC-virus group: positive for $\mathrm{HBsAg}$ and/or positive for $\mathrm{HCV} \mathrm{Ab}$, and ii) 74 were included in the HCC-nonBC group: negative for both $\mathrm{HBsAg}$ and $\mathrm{HCV} \mathrm{Ab}$. The follow-up patterns until the initial detection of HCC and the survival rates were analyzed and compared between the 2 groups. Multivariate analysis identified followup, alcohol consumption, albumin level, total bilirubin level, $\alpha$-fetoprotein (AFP) level, and tumor-node-metastasis (TNM) stage as independent and significant risk factors for prognosis. Among the 397 patients with HCC in TNM stage I or II, multivariate analysis identified the cause of liver disease, gender, Child-Pugh score, serum albumin level and TNM stage as independent and significant risk factors for prognosis. We reported that the poor prognoses of patients with HCCnonBC were attributable to its late detection in an advanced condition due to the absence of a surveillance system for the early detection of HCC. However, in early-stage patients, patients with HCC-nonBC showed significantly better prognosis than those in the HCC-virus group.
\end{abstract}

Correspondence to: Dr Naota Taura, Department of Gastroenterology and Hepatology, Graduate School of Biomedical Sciences, Nagasaki University, Sakamoto 1-7-1, Nagasaki 8528501, Japan

E-mail: ntaura-gi@umin.ac.jp

Key words: hepatocellular carcinoma, viral hepatitis

\section{Introduction}

Primary liver cancer is the most common cancer of the liver, accounting for approximately $6 \%$ of all human cancers. It is estimated that half a million cases of this disease occur worldwide each year, making primary liver cancer the fifth most common malignancy in men and the ninth in women (1-6). Hepatocellular carcinoma (HCC) accounts for 85 to $90 \%$ of primary liver cancers, (7) and the age-adjusted HCC mortality rate has increased over the past few decades in Japan (8). Similarly, a trend in increasing incidence rates of HCC has been reported for several developed countries in North America, Europe and Asia $(9,10)$. HCC often develops in patients with liver cirrhosis caused by hepatitis B virus (HBV), hepatitis C virus (HCV), excessive alcohol consumption or nonalcoholic fatty liver disease. $\mathrm{HCV}$ is the predominant causative agent of HCC in Japan (11-14). However, it has been reported that the number and ratio of both $\mathrm{HBsAg}$ - and $\mathrm{HCV}$ Ab-negative HCC (HCC-nonBC) have been steadily increasing in Japan $(15,16)$.

The prognosis for patients with HCC is still poor. Surgical resection and liver transplantation are the standard treatment methods available. Radiofrequency ablation (RFA) and percutaneous ethanol injection (PEI) have recently been recognized as effective methods of achieving complete tumor necrosis in small HCCs (17); however, the chances of curative treatment are often limited by several features of HCC. HCCs usually grow to a large size before symptom manifestation. Bilobar or multifocal tumors are common, and the incidence of associated cirrhosis is high, being over $80 \%$ in most cases (18-20). Transcatheter arterial chemoembolization (TACE), which is considered to be an ineffective method of achieving complete necrosis of HCCs, also depends on the above factors (21). Early detection of HCC by $\alpha$-fetoprotein (AFP) and/or imaging screening has been implemented in many countries to increase the chances of successful intervention and to improve survival (22-26).

The aim of this study was to examine the frequency of detection of HCC-nonBC by screening methods and elucidate the differences in the clinical characteristics between non- $\mathrm{B}$, non-C HCC and hepatitis $\mathrm{C}$ and/or B virus-associated HCC (HCC-virus). 


\section{Patients and methods}

Patients and study groups. We recruited 624 patients with HCC who were diagnosed between January, 1982 and December, 2007 at the Department of Gastroenterology and Hepatology, Nagasaki University Hospital. Informed consent was obtained from all patients. The diagnosis of HCC was based on AFP levels; results of imaging techniques such as ultrasonography (USG), computerized tomography (CT), magnetic resonance imaging (MRI) and hepatic angiography (HAG); and/or liver biopsy. The diagnostic criteria included characteristic liver biopsy findings, elevated AFP ( $\geq 20 \mathrm{ng} / \mathrm{ml}$ ) and neovascularization on $\mathrm{HAG}$ and/or CT.

Sera were stored at $-80^{\circ} \mathrm{C}$ until they were used for the following assays. The diagnosis of chronic hepatitis $\mathrm{C}$ virus (HCV) infection was based on the presence of $\mathrm{HCV} \mathrm{Ab}$ (microparticle enzyme immunoassay; Abbott Laboratories) and HCV RNA as detected by polymerase chain reaction. The diagnosis of chronic HBV infection was based on the presence of HBsAg (enzyme-linked immunosorbent assay; Abbott Laboratories); the serum AFP level was measured by radioimmunoassay (Abbott Laboratories). The history of alcohol intake was noted from medical records; habitual drinking was defined as an average daily consumption of an amount equivalent to $80 \mathrm{~g}$ of pure ethanol for a period of more than 10 years.

The patients were categorized into 2 groups as follows: i) HCC-virus group (550) comprising patients positive for HBsAg and/or positive for $\mathrm{HCV} \mathrm{Ab}$ and ii) $\mathrm{HCC}$-nonBC group (74) comprising patients negative for both $\mathrm{HBsAg}$ and $\mathrm{HCV} \mathrm{Ab}$. We analyzed and compared the 2 groups for age distribution, gender ratio, body-mass index, alcohol intake, serum AFP level, tumor-node metastasis (TNM) stage of hepatocellular carcinoma tumors at the time of initial detection, Child-Pugh score, follow-up pattern until the initial detection of HCC and the survival rates.

Follow-up. All patients were categorized into 2 groups: the follow-up group included $365(58 \%)$ patients with subclinical HCC diagnosed by screening; the non-follow-up group consisted of 259 (42\%) patients who were diagnosed at our hospital owing to the appearance of symptoms indicative of HCC. AFP levels and liver function were assessed every 3 to 6 months, and USG or CT imaging was performed every 3 to 12 months over a period of at least 12 months prior to the diagnosis of HCC in patients of the follow-up group. The nonfollow-up group patients presented with clinical symptoms such as abdominal pain, discomfort, nausea or weight loss which led to the evaluation and diagnosis of HCC.

Treatment modalities. Patients diagnosed with HCC were assessed for surgery on the basis of the extent of lobar involvement and liver function status. The extent of lobar involvement was evaluated by a combination of USG, CT, MRI and HAG. Patients were considered unfit for resection when they met the following criteria: i) bilobar involvement, ii) evidence of tumor infiltration into the main portal vein or thrombosis of the vein, iii) evidence of extrahepatic metastases, iv) Child's grade $\mathrm{C}$ cirrhosis or v) poor cardiac and respiratory statuses. If the patients were deemed unfit for operation or refused to undergo operation, PEI therapy was the second choice of treatment offered to such patients with HCCs $<3 \mathrm{~cm}$ in diameter. The remaining patients without main portal vein thrombosis or extrahepatic metastasis were advised to undergo TACE irrespective of the size and number of tumors.

After initial treatment, AFP levels and liver function of the patients were assessed every 1 to 3 months, and USG imaging was performed every 3 to 6 months during the follow-up period. Patients suspected to have HCC recurrence were further evaluated by CT and/or MRI. The assessment of treatment for recurrent HCC was based on lobar involvement and liver function status as described for the initial treatment. RFA or liver transplantation to treat HCC was started at our institution in 2002; none of the patients were treated by these methods between 1982 and 2001. Furthermore, none of the subjects in our study received either of these treatments for recurrent $\mathrm{HCC}$ during the follow-up period.

Statistical analysis. The time of survival was measured from the time of the diagnosis of HCC to the time of death or until the time of preparation of the manuscript. The data were analyzed by the Mann-Whitney test for continuous ordinal data, and the Chi-square test with Yates' correction and Fisher's exact test were performed for intergroup comparisons to determine the association between 2 qualitative variables. The survival rate was analyzed using the Kaplan-Meier method, and the differences between the survival probability curves were tested using the log-rank test. The independent risk factors associated with the rate of survival were estimated by the non-time-dependent stepwise Cox regression analysis. The standard error was calculated based on the binomial model to estimate the response rate. A value $\mathrm{P}<0.05$ was considered statistically significant. Data analysis was performed with SPSS version 16.0 software for Windows.

\section{Results}

Patient characteristics at enrollment. We diagnosed 624 patients with HCC during the study period. Patient characteristics at the time of diagnosis of HCC are presented in Table I. The underlying causes of HCC were determined to be as follows: 120 (19\%) patients were positive for HBsAg, 411 (66\%) were positive for HCV Ab, 19 (3\%) were positive for both HBsAg and HCV Ab and 74 (12\%) were negative for $\mathrm{HBsAg}$ and anti-HCV.

Comparison of clinical characteristics and survival between patients with and without hepatitis virus infection. The patients were divided into 2 groups: the HCC-nonBC group (74 patients) and the HCC-virus group (550 patients); the characteristics of each group were compared (Table I). There were no significant differences in gender, BMI, Child-Pugh score, prothrombin time, or albumin and total bilirubin levels. However, there were significant differences between the 2 groups in terms of median age $(\mathrm{P}=0.001)$, habitual drinkers $(\mathrm{P}=0.015)$, TNM stage $(\mathrm{P}=0.030)$, AFP $(\mathrm{P}=0.002)$ and follow-up group $(\mathrm{P}=0.010)$. The HCC-nonBC group had a lower proportion of patients who were followed up when compared to those of the HCC-virus group.

Table II indicates the results of univariate and multivariate analyses of the prognosis factors for HCC using the 
Table I. Comparison between HCC patients with and without virus infection.

\begin{tabular}{|c|c|c|c|c|c|c|c|}
\hline \multirow[b]{2}{*}{ Total } & \multicolumn{2}{|c|}{ All patients } & \multicolumn{2}{|c|}{ HCC-nonBC } & \multicolumn{2}{|c|}{ HCC-virus } & \multirow[t]{2}{*}{ P-value } \\
\hline & 624 & & 74 & & 550 & & \\
\hline Median age, years & 65 & (13) & 70 & (6) & 64 & (12) & 0.001 \\
\hline \multicolumn{8}{|l|}{ Gender $(\%)$} \\
\hline Male & 478 & (77) & 54 & (73) & 424 & (77) & \\
\hline Female & 146 & $(23)$ & 20 & (27) & 126 & (23) & NS \\
\hline BMI & 22.4 & $(4.2)$ & 23.1 & $(6.0)$ & 22.3 & $(4.8)$ & $\mathrm{NS}$ \\
\hline \multicolumn{8}{|l|}{ Alcohol consumption $(\%)$} \\
\hline Not excessive & 497 & $(80)$ & 51 & $(69)$ & 446 & $(81)$ & \\
\hline Excessive & 127 & $(20)$ & 23 & $(31)$ & 104 & (19) & 0.015 \\
\hline \multicolumn{8}{|l|}{ Follow-up (\%) } \\
\hline Follow-up group & 365 & $(58)$ & 33 & $(45)$ & 332 & $(60)$ & \\
\hline Non-follow-up group & 259 & $(42)$ & 41 & $(55)$ & 218 & $(40)$ & 0.010 \\
\hline Child-Pugh score & 6 & (1) & 5 & (2) & 6 & (2) & $\mathrm{NS}$ \\
\hline \multicolumn{8}{|l|}{ Hepatitis virus } \\
\hline HBsAg (+)/HCV Ab (-) & 120 & (19) & 0 & $(0)$ & 120 & $(22)$ & \\
\hline HBsAg $(-) / \mathrm{HCV} \mathrm{Ab}(+)$ & 411 & $(66)$ & 0 & $(0)$ & 411 & (75) & \\
\hline HBsAg $(+) / \mathrm{HCV} \mathrm{Ab}(+)$ & 19 & (3) & 0 & $(0)$ & 19 & (3) & \\
\hline HBsAg (-)/HCV Ab (-) & 74 & $(12)$ & 74 & $(100)$ & 0 & $(0)$ & - \\
\hline \multicolumn{8}{|l|}{ TNM stage $(\%)$} \\
\hline I & 158 & $(25)$ & 11 & (15) & 147 & $(27)$ & \\
\hline II & 239 & $(38)$ & 30 & $(40)$ & 209 & (39) & \\
\hline III & 142 & (23) & 20 & $(27)$ & 122 & $(22)$ & \\
\hline IV & 85 & (14) & 13 & (18) & 72 & $(12)$ & 0.030 \\
\hline \multicolumn{8}{|l|}{ Laboratory data } \\
\hline Albumin $(\mathrm{g} / \mathrm{dl})$ & 3.7 & $(0.8)$ & 3.8 & $(0.9)$ & 3.7 & $(0.8)$ & NS \\
\hline Prothrombin time $(\%)$ & 80 & $(22)$ & 85 & $(22)$ & 80 & $(22)$ & NS \\
\hline Total bilirubin (mg/dl) & 1.0 & $(0.8)$ & 0.9 & $(0.7)$ & 1.0 & $(0.8)$ & NS \\
\hline $\mathrm{AFP}(\mathrm{ng} / \mathrm{ml})$ & 51 & $(446)$ & 16 & $(290)$ & 59 & $(452)$ & 0.002 \\
\hline
\end{tabular}

Data are median (IQR) or frequency (\%). NS, not significant.

Cox proportional hazards model. Univariate analysis revealed that 9 of 12 factors (male, excessive alcohol intake, Child-Pugh score $\geq 7$, albumin $<3.7 \mathrm{~g} / \mathrm{dl}$, prothrombin time $<80 \%$, total bilirubin $\geq 1.1 \mathrm{mg} / \mathrm{dl}$, AFP $\geq 52 \mathrm{ng} / \mathrm{ml}$, TNM stage III or IV, and the follow-up group) significantly affected the survival rate in patients with HCC. Multivariate analysis identified follow-up (follow-up group, relative risk 0.71), alcohol consumption (excessive drinker, relative risk $1.32)$, albumin $(<3.7 \mathrm{~g} / \mathrm{dl}$, relative risk 1.37), total bilirubin $(\geq 1.1 \mathrm{mg} / \mathrm{dl}$, relative risk 1.53), AFP ( $\geq 52 \mathrm{ng} / \mathrm{ml}$, relative risk 1.44 ), and TNM stage (III or IV, relative risk 2.50), as independent and significant risk factors $(\mathrm{P}=0.002,0.043$, $0.046,<0.001,0.001$ and $<0.001$, respectively) for prognosis.

Comparison of clinical characteristics and survival between patients with and without hepatitis virus infection in those patients with TNM stage I or II. Characteristics of patients with TNM stage I or II at the time of HCC diagnosis are presented in Table III. No significant differences were observed in gender, habitual drinkers, BMI, TNM stage, prothrombin time, or total bilirubin level. However, there were significant differences in the median age $(\mathrm{P}<0.001)$, Child-Pugh score $(\mathrm{P}=0.012)$, albumin level $(\mathrm{P}=0.009)$, AFP $(\mathrm{P}<0.001)$ and follow-up group $(\mathrm{P}=0.010)$.

Table IV indicates the results of univariate and multivariate analyses of the prognosis factors for HCC using the Cox proportional hazards model. Univariate analysis revealed that 6 of 12 factors (male, Child-Pugh score $\geq 7$, albumin $<3.7 \mathrm{~g} / \mathrm{dl}$, AFP $\geq 52 \mathrm{ng} / \mathrm{ml}$, TNM stage II and HCC-nonBC) significantly affected the survival rate in $\mathrm{HCC}$ patients. Multivariate analysis identified HCC-nonBC (HCC-nonBC, relative risk 0.55), gender (male, relative risk 1.58), ChildPugh score $(\geq 7$, relative risk 1.47$)$, albumin $(<3.8 \mathrm{~g} / \mathrm{dl}$, relative risk 1.62) and TNM stage (stage II, relative risk 
Table II. Univariate and multivariate analyses of prognostic factors for HCC in the 624 patients.

\begin{tabular}{|c|c|c|c|c|c|}
\hline \multirow[b]{2}{*}{ Variable } & & \multicolumn{2}{|c|}{ Univariate analysis } & \multicolumn{2}{|c|}{ Multivariate analysis } \\
\hline & & P-value & Relative risk (95\% CI) & P-value & Relative risk $(95 \% \mathrm{CI})$ \\
\hline Age (years ) & $\geq 65$ & 0.058 & $0.82(0.67-1.01)$ & & \\
\hline Gender & Male & $0.003^{\mathrm{a}}$ & $1.46(1.14-1.88)$ & 0.800 & $1.28(0.97-1.68)$ \\
\hline BMI & $\geq 25$ & 0.177 & $0.84(0.65-1.08)$ & & \\
\hline Alcohol consumption & Excessive & $0.011^{\mathrm{a}}$ & $1.37(1.08-1.75)$ & $0.043^{\mathrm{a}}$ & $1.32(1.01-1.72)$ \\
\hline Follow-up & Followed up & $<0.001^{\mathrm{a}}$ & $0.63(0.52-0.77)$ & $0.002^{\mathrm{a}}$ & $0.71(0.56-0.89)$ \\
\hline Child-Pugh score & $\geq 7$ & $<0.001^{\mathrm{a}}$ & $2.10(1.70-2.59)$ & 0.134 & $1.30(0.92-1.82)$ \\
\hline Albumin $(\mathrm{g} / \mathrm{dl})$ & $<3.7$ & $<0.001^{\mathrm{a}}$ & $1.98(1.62-2.43)$ & $0.046^{\mathrm{a}}$ & $1.37(1.01-1.85)$ \\
\hline Prothrombin time (\%) & $<80$ & $0.002^{\mathrm{a}}$ & $1.37(1.12-1.68)$ & 0.959 & $0.99(0.78-1.27)$ \\
\hline Total bilirubin (mg/dl) & $\geq 1.1$ & $<0.001^{\mathrm{a}}$ & $1.67(1.36-2.05)$ & $<0.001^{\mathrm{a}}$ & $1.53(1.22-1.92)$ \\
\hline $\operatorname{AFP}(\mathrm{ng} / \mathrm{ml})$ & $\geq 52$ & $<0.001^{\mathrm{a}}$ & $1.83(1.49-2.24)$ & $0.001^{\mathrm{a}}$ & $1.44(1.16-1.79)$ \\
\hline TNM stage & III or IV & $<0.001^{\mathrm{a}}$ & $3.02(2.45-3.72)$ & $<0.001^{\mathrm{a}}$ & $2.50(2.00-3.13)$ \\
\hline Etiology of liver disease & HCC-nonBC & 0.139 & $0.77(0.54-1.09)$ & & \\
\hline
\end{tabular}

CI, confidence interval.

Table III. Comparison between HCC in TNM stage I or II patients with and without virus infection.

\begin{tabular}{|c|c|c|c|c|c|c|c|}
\hline \multirow[b]{2}{*}{ Total } & \multicolumn{2}{|c|}{ All patients } & \multicolumn{2}{|c|}{ HCC-nonBC } & \multicolumn{2}{|c|}{ HCC-virus } & \multirow[t]{2}{*}{ P-value } \\
\hline & 397 & & 41 & & 356 & & \\
\hline Median age, years & 65 & (13) & 72 & (13) & 65 & (13) & $<0.001$ \\
\hline \multicolumn{8}{|l|}{ Gender (\%) } \\
\hline Male & 288 & (73) & 27 & $(66)$ & 261 & (73) & \\
\hline Female & 109 & $(27)$ & 14 & (34) & 95 & $(27)$ & NS \\
\hline BMI & 22.3 & $(4.0)$ & 23.7 & $(5.2)$ & 22.3 & $(3.9)$ & NS \\
\hline \multicolumn{8}{|l|}{ Alcohol consumption (\%) } \\
\hline Not excessive & 328 & $(83)$ & 31 & (76) & 297 & $(83)$ & \\
\hline Excessive & 69 & (17) & 10 & (24) & 59 & (17) & NS \\
\hline \multicolumn{8}{|l|}{ Follow-up (\%) } \\
\hline Follow-up group & 268 & $(68)$ & 21 & $(51)$ & 247 & $(60)$ & \\
\hline Non-follow-up group & 129 & $(32)$ & 20 & (49) & 109 & (40) & 0.019 \\
\hline Child-Pugh score & 6 & (2) & 5 & $(1)$ & 6 & (2) & 0.012 \\
\hline \multicolumn{8}{|l|}{ Hepatitis virus } \\
\hline HBsAg (+)/HCV Ab (-) & 70 & $(18)$ & 0 & $(0)$ & 70 & $(20)$ & \\
\hline HBsAg $(-) / \mathrm{HCV} \mathrm{Ab}(+)$ & 274 & (69) & 0 & $(0)$ & 274 & (77) & \\
\hline $\mathrm{HBsAg}(+) / \mathrm{HCV} \mathrm{Ab}(+)$ & 12 & (3) & 0 & $(0)$ & 12 & (3) & \\
\hline HBsAg (-)/HCV Ab (-) & 40 & $(10)$ & 40 & $(100)$ & 0 & $(0)$ & - \\
\hline \multicolumn{8}{|l|}{ TNM stage (\%) } \\
\hline I & 158 & $(40)$ & 11 & $(15)$ & 147 & $(27)$ & \\
\hline II & 239 & $(60)$ & 30 & $(40)$ & 209 & $(39)$ & NS \\
\hline \multicolumn{8}{|l|}{ Laboratory data } \\
\hline Albumin (g/dl) & 3.8 & $(0.7)$ & 4.0 & $(0.6)$ & 3.8 & $(0.8)$ & 0.009 \\
\hline Prothrombin time $(\%)$ & 82 & $(22)$ & 87 & $(20)$ & 80 & $(21)$ & NS \\
\hline Total bilirubin (mg/dl) & 0.9 & $(0.6)$ & 0.8 & $(0.4)$ & 1.0 & $(0.7)$ & NS \\
\hline $\mathrm{AFP}(\mathrm{ng} / \mathrm{ml})$ & 32 & $(222)$ & 9 & $(32)$ & 36 & $(254)$ & $<0.001$ \\
\hline
\end{tabular}

Data are median (IQR) or frequency (\%). NS, not significant. 
Table IV. Univariate and multivariate analyses of prognostic factors for HCC in patients with TNM stage I or II.

\begin{tabular}{|c|c|c|c|c|c|}
\hline \multirow[b]{2}{*}{ Variable } & & \multicolumn{2}{|c|}{ Univariate analysis } & \multicolumn{2}{|c|}{ Multivariate analysis } \\
\hline & & P-value & Relative risk (95\% CI) & P-value & Relative risk $(95 \% \mathrm{CI})$ \\
\hline Age (years) & $\geq 65$ & 0.514 & $0.91(0.69-1.20)$ & & \\
\hline Gender & Male & $0.039^{\mathrm{a}}$ & $1.40(1.02-1.94)$ & $0.008^{\mathrm{a}}$ & $1.58(1.13-2.21)$ \\
\hline BMI & $\geq 25$ & 0.062 & $0.71(0.50-1.02)$ & & \\
\hline Alcohol consumption & Excessive & 0.083 & $1.36(1.96-1.93)$ & & \\
\hline Follow-up & Followed up & 0.270 & $0.85(0.64-1.13)$ & & \\
\hline Child-Pugh score & $\geq 7$ & $<0.001^{\mathrm{a}}$ & $2.04(1.52-2.73)$ & $0.041^{\mathrm{a}}$ & $1.47(1.02-2.11)$ \\
\hline Albumin (g/dl) & $<3.8$ & $<0.001^{\mathrm{a}}$ & $2.04(1.56-2.68)$ & $0.007^{\mathrm{a}}$ & $1.62(1.15-2.30)$ \\
\hline Prothrombin time (\%) & $<82$ & 0.083 & $1.27(0.97-1.67)$ & & \\
\hline Total bilirubin (mg/dl) & $\geq 0.9$ & 0.067 & $1.30(0.98-1.72)$ & & \\
\hline $\operatorname{AFP}(n g / m l)$ & $\geq 32$ & $<0.001^{\mathrm{a}}$ & $1.64(1.26-2.16)$ & 0.065 & $1.31(0.98-1.74)$ \\
\hline TNM stage & II & $0.004^{\mathrm{a}}$ & $1.52(1.14-2.01)$ & $0.004^{\mathrm{a}}$ & $1.53(1.14-2.04)$ \\
\hline Etiology of liver disease & HCC-nonBC & $0.020^{\mathrm{a}}$ & $0.51(0.29-0.90)$ & $0.048^{\mathrm{a}}$ & $0.55(0.30-0.99)$ \\
\hline
\end{tabular}

CI, confidence interval.

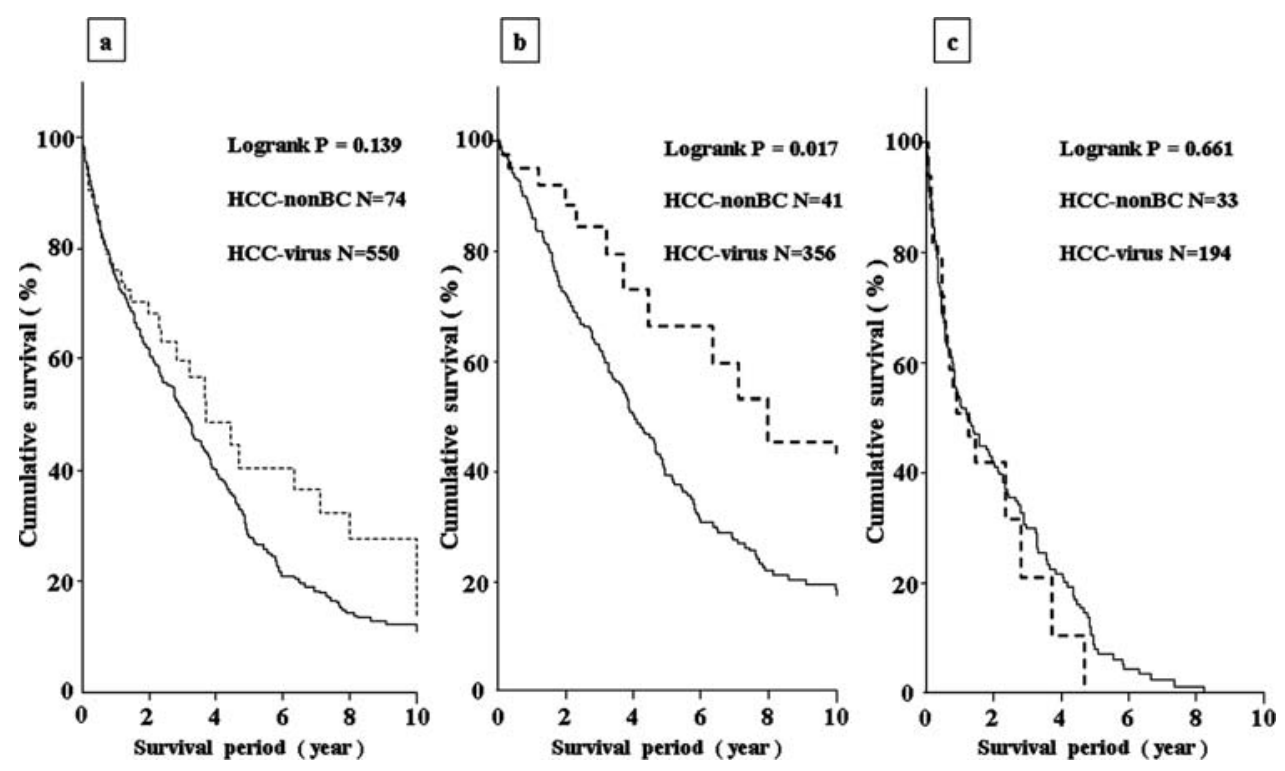

Figure 1. The cumulative survival rate in HCC patients without hepatitis virus infection (HCC-nonBC, dashed-line) and in HCC patients infected with hepatitis virus (HCC-virus, thin line) according to the TNM staging system.

$1.53)$, as independent and significant risk factors $(\mathrm{P}=0.048$, $0.008,0.041,0.007$ and 0.004 , respectively) for prognosis.

Patient survival. Overall, the median survival of all 624 patients was 1.84 years. No significant difference was detected in the survival rate between patients with and without hepatitis virus infection (Fig. 1a). When patients were classified according to the TNM stage, patients in the HCC-nonBC group with TNM stage I or II had a higher cumulative survival rate than those in the HCC-virus group (Fig. 1b; $\mathrm{P}=0.017$ ). Patients who had TNM stage III or IV and HCCnonBC and HCC-virus patients did not show significant differences in survival rates (Fig. 1c).

\section{Discussion}

The age-adjusted mortality rate for HCC has increased over the past few decades in Japan (27). However, the majority of patients are still diagnosed at an advanced stage and so have a short survival time after diagnosis. Patients with chronic $\mathrm{HBV}$ and/or HCV infection complicated by cirrhosis should be monitored with ultrasonography, CT or MRI of the liver to detect tumors at an early stage. In $58 \%$ of our patients, the tumors were detected on follow-up. Patients in the follow-up group had smaller tumors at the time of diagnosis and were more likely to be eligible for treatment. In addition, there was a significant improvement in survival rates among the 
follow-up group (24-26,28-32). We recognized that the 2 groups of patients could not be evaluated in a prospective study, and improved survival in the follow-up group patients may be owing to the effect of lead-time bias. Nevertheless, our data corroborate those of previous studies indicating that follow-up may have increased rates of early detection and eligibility for curative treatment, which may in turn translate to improved survival.

In the TNM stages I and II, patients with HCC-nonBC had a better prognosis than those with HCC-virus. This difference may be explained as follows. HCC secondary to liver cirrhosis is less frequent in patients with HCC-nonBC than in those with HCC-virus (12). Patients with HCC-nonBC are less likely to progress to liver cirrhosis (33). However, in the TNM stage III and IV, the patients with HCC-nonBC had a similar prognosis to those with HCC-virus. The percentages of advanced stage $\mathrm{HCC}$ and non-follow-up patients were significantly higher in the HCC-nonBC group than in the HCC-virus group. Taken together, these results indicate that the prognosis of patients with HCC-nonBC is linked to the follow-up studies for detecting HCC.

A large proportion of people infected with $\mathrm{HCV}, \mathrm{HBV}$ or both have latent cancer. Therefore, it is essential that HCC is detected at an early stage in individuals who harbor chronic $\mathrm{HCV}$ or HBV infections. In this study, more than $80 \%$ of patients had HCC associated with $\mathrm{HBV}$ and/or HCV; therefore, the target population for the surveillance of HCC must be easily identifiable. However, the incidence of hepatitis virus associated with HCC will decrease in Japan $(15,34,35)$ because of the following reasons. In Japan, the population of individuals infected with chronic $\mathrm{HCV}$ is rapidly aging $(36,37)$, and chronic HBV infection has been preventable since the licensing of the hepatitis B vaccine in 1982. In fact, primary tumors in $12 \%$ of our patients with HCC were negative for both $\mathrm{HBsAg}$ and $\mathrm{HCV} \mathrm{Ab}$. Of these, nonalcoholic fatty liver disease (NAFLD) may be a cause of HCC. Bugianesi et al suggested that liver disease was caused by NAFLD in 23/641 (4\%) patients with HCC (38). However, it will be difficult to select patients for the screening of HCC, who are negative for both HBsAg and HCV Ab.

HCC surveillance for patients eligible for imaging tests is usually performed at 6-month intervals. Additionally, a combined imaging test and a serological test such as AFP or des- $\gamma$ carboxy prothrombin is a sensitive method to detect HCC $(29,39)$. The target population for the surveillance of HCC may not be easily identified in Japan. It has been reported previously that more than $60 \%$ of patients in the follow-up group had HCCs measuring less than $3 \mathrm{~cm}$ in diameter (26). It is possible that 12-month intervals for the imaging test were reasonable to ensure the detection of treatable tumors in patients with HCC.

In summary, the poorer prognosis of patients with HCCnonBC was attributable to its late detection in an advanced condition, owing to the lack of a surveillance system for early detection of HCC. However, among early-stage patients, those with HCC-nonBC showed a significantly better prognosis than those with HCC-virus. To conclude, we suggest that the entire population of Japan should be tested using imaging techniques at least every 12 months along with an abdominal examination.

\section{References}

1. El-Serag HB and Mason AC: Risk factors for the rising rates of primary liver cancer in the United States. Arch Intern Med 160: 3227-3230, 2000.

2. El-Serag HB: Epidemiology of hepatocellular carcinoma. Clin Liver Dis 5: 87-107, 2001.

3. El-Serag HB, Hampel H, Yeh C and Rabeneck L: Extrahepatic manifestations of hepatitis $\mathrm{C}$ among United States male veterans. Hepatology 36: 1439-1445, 2002.

4. El-Serag HB: Hepatocellular carcinoma and hepatitis $\mathrm{C}$ in the United States. Hepatology 36: S74-S83, 2002.

5. El-Serag HB: Hepatocellular carcinoma: an epidemiologic view. J Clin Gastroenterol 35: S72-S78, 2002.

6. Hassan MM, Frome A, Patt YZ and El-Serag HB: Rising prevalence of hepatitis $\mathrm{C}$ virus infection among patients recently diagnosed with hepatocellular carcinoma in the United States. J Clin Gastroenterol 35: 266-269, 2002.

7. El-Serag HB and Rudolph KL: Hepatocellular carcinoma: epidemiology and molecular carcinogenesis. Gastroenterology 132: 2557-2576, 2007.

8. Kiyosawa $\mathrm{K}$ and Tanaka E: Characteristics of hepatocellular carcinoma in Japan. Oncology 62: 5-7, 2002.

9. McGlynn KA, Tsao L, Hsing AW, Devesa SS and Fraumeni JF Jr: International trends and patterns of primary liver cancer. Int $\mathrm{J}$ Cancer 94: 290-296, 2001.

10. Bosch FX, Ribes J, Diaz M and Cleries R: Primary liver cancer: worldwide incidence and trends. Gastroenterology 127: S5-S16, 2004.

11. Hamasaki K, Nakata K, Tsutsumi T, et al: Changes in the prevalence of hepatitis $\mathrm{B}$ and $\mathrm{C}$ infection in patients with hepatocellular carcinoma in the Nagasaki Prefecture, Japan. J Med Virol 40: 146-149, 1993.

12. Kato Y, Nakata K, Omagari K, et al: Risk of hepatocellular carcinoma in patients with cirrhosis in Japan. Analysis of infectious hepatitis viruses. Cancer 74: 2234-2238, 1994.

13. Shiratori Y, Shiina S, Imamura M, et al: Characteristic difference of hepatocellular carcinoma between hepatitis B- and C-viral infection in Japan. Hepatology 22: 1027-1033, 1995.

14. Shiratori Y, Shiina S, Zhang PY, et al: Does dual infection by hepatitis $\mathrm{B}$ and $\mathrm{C}$ viruses play an important role in the pathogenesis of hepatocellular carcinoma in Japan? Cancer 80: 2060-2067, 1997.

15. Taura N, Yatsuhashi H, Nakao K, Ichikawa T and Ishibashi H: Long-term trends of the incidence of hepatocellular carcinoma in the Nagasaki prefecture, Japan. Oncol Rep 21: 223-227, 2009.

16. Hatanaka K, Kudo M, Fukunaga T, et al: Clinical characteristics of NonBNonC-HCC: Comparison with $\mathrm{HBV}$ and $\mathrm{HCV}$ related HCC. Intervirology 50: 24-31, 2007.

17. Omata M, Tateishi R, Yoshida H and Shiina S: Treatment of hepatocellular carcinoma by percutaneous tumor ablation methods: Ethanol injection therapy and radiofrequency ablation. Gastroenterology 127: S159-S166, 2004.

18. Calvet X, Bruix J, Gines P, et al: Prognostic factors of hepatocellular carcinoma in the West: a multivariate analysis in 206 patients. Hepatology 12: 753-760, 1990.

19. Schafer DF and Sorrell MF: Hepatocellular carcinoma. Lancet 353: 1253-1257, 1999.

20. Akriviadis EA, Llovet JM, Efremidis SC, et al: Hepatocellular carcinoma. Br J Surg 85: 1319-1331, 1998.

21. Ngan H, Lai CL, Fan ST, Lai EC, Yuen WK and Tso WK: Transcatheter arterial chemoembolization in inoperable hepatocellular carcinoma: four-year follow-up. J Vasc Interv Radiol 7: 419-425, 1996.

22. Oka H, Kurioka N, Kim K, et al: Prospective study of early detection of hepatocellular carcinoma in patients with cirrhosis. Hepatology 12: 680-687, 1990.

23. Lai CL, Lau JY, Wu PC, et al: Subclinical hepatocellular carcinoma in Hong Kong Chinese. Oncology 49: 347-353, 1992.

24. Colombo M, de Franchis R, Del Ninno E, et al: Hepatocellular carcinoma in Italian patients with cirrhosis. N Engl J Med 325: 675-680, 1991.

25. Pateron D, Ganne N, Trinchet JC, et al: Prospective study of screening for hepatocellular carcinoma in Caucasian patients with cirrhosis. J Hepatol 20: 65-71, 1994.

26. Taura N, Hamasaki K, Nakao K, et al: Clinical benefits of hepatocellular carcinoma surveillance: a single-center, hospitalbased study. Oncol Rep 14: 999-1003, 2005. 
27. Wada I, Hara T, Kajihara S, et al: Population-based study of hepatitis $\mathrm{C}$ virus infection and hepatocellular carcinoma in western Japan. Hepatol Res 23: 18-24, 2002.

28. Livraghi T, Bolondi L, Buscarini L, et al: No treatment, resection and ethanol injection in hepatocellular carcinoma: a retrospective analysis of survival in 391 patients with cirrhosis Italian Cooperative HCC Study Group. J Hepatol 22: 522-526, 1995.

29. Dohmen K, Shirahama M, Onohara S, et al: Differences in survival based on the type of follow-up for the detection of hepatocellular carcinoma: an analysis of 547 patients. Hepatol Res 18: 110-121, 2000.

30. Bolondi L, Sofia S, Siringo S, et al: Surveillance programme of cirrhotic patients for early diagnosis and treatment of hepatocellular carcinoma: a cost effectiveness analysis. Gut 48: 251-259, 2001.

31. Yuen MF, Cheng CC, Lauder IJ, Lam SK, Ooi CG and Lai CL: Early detection of hepatocellular carcinoma increases the chance of treatment: Hong Kong experience. Hepatology 31: $330-335,2000$

32. Marrero JA, Fontana RJ, Su GL, Conjeevaram HS, Emick DM and Lok AS: NAFLD may be a common underlying liver disease in patients with hepatocellular carcinoma in the United States. Hepatology 36: 1349-1354, 2002.
33. Watabe H, Shiratori Y, Tateishi R, et al: Clinical features of patients with $\mathrm{HCC}$ who are negative for both $\mathrm{HBV}$ and $\mathrm{HCV}$ markers. Hepatogastroenterology 50: 2157-2160, 2003.

34. Kiyosawa K, Umemura T, Ichijo T, et al: Hepatocellular carcinoma: recent trends in Japan. Gastroenterology 127: S17-S26, 2004

35. Umemura T and Kiyosawa K: Epidemiology of hepatocellular carcinoma in Japan. Hepatol Res 37 (Suppl 2): 95-100, 2007.

36. Yoshizawa H: Hepatocellular carcinoma associated with hepatitis $\mathrm{C}$ virus infection in Japan: projection to other countries in the foreseeable future. Oncology 62: 8-17, 2002.

37. Taura N, Hamasaki K, Nakao K, et al: Aging of patients with hepatitis $\mathrm{C}$ virus-associated hepatocellular carcinoma: long-term trends in Japan. Oncol Rep 16: 837-843, 2006.

38. Bugianesi E, Leone N, Vanni E, et al: Expanding the natural history of nonalcoholic steatohepatitis: from cryptogenic cirrhosis to hepatocellular carcinoma. Gastroenterology 123: 134-140, 2002.

39. Okuda H, Nakanishi T, Takatsu K, et al: Comparison of clinicopathological features of patients with hepatocellular carcinoma seropositive for alpha-fetoprotein alone and those seropositive for des-gamma-carboxy prothrombin alone. J Gastroenterol Hepatol 16: 1290-1296, 2001. 